\title{
Installment Joint Life Insurance Actuarial Models with the Stochastic Interest Rate
}

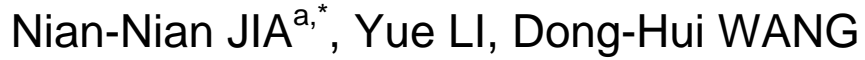 \\ College of Science, Harbin Engineering University, Harbin, 150001, China \\ ajianiannian@hrbeu.edu.cn \\ ${ }^{*}$ Corresponding author
}

Keywords: Stochastic interest rate, Installment payment, Combine life insurance, Net level premium, Reserve.

\begin{abstract}
Actuarial theory in a stochastic interest rate environment is an active research area in life insurance. Installment joint life insurance actuarial theories are one of the key contents in actuarial theory. In this study, an interest force accumulation function model with a Wiener process and a Poisson process is proposed as the basis for the installment joint life insurance actuarial models. Then increasing life insurance actuarial models with the consumer price index are approximated. With the proposed model, the net single premium, net level premium, the reserves and the risk of loss model are provided. The actuarial models in the paper provide a feasible method to calculate the life insurance premium.
\end{abstract}

\section{Introduction}

The actuarial originates from the calculation of life insurance premium, but in China, life insurance industry develops slowly. Until the late 1980s, China introduces the life insurance actuarial science, and then scholars begin to study on the life insurance actuarial science. In foreign countries, Panjer [1] (1980) built the life insurance actuarial models under the stochastic interest rate and sudden mortality rate, and he studied the statistical properties of the interest rate and the annuity. Beekman [2] (1990) advanced a new model. The model raised stochastic phenomena of interest rate and the future life, and Beekman draw the expression of annuity and net single premium. In China, Qingrong Jiang [3](1997) for the first time regarded the interest rate as the independent and identical distribution, then he calculated the corresponding premium with this condition. Wenjiong He [4] (1998) and Qingrong Jiang used the Gauss process to simulate changes in the interest rate. They calculated the net single premium and the variance. The literature simulates stochastic interest rate in many ways, such as Time Series Analysis, auto-regressive integrated moving average, Brownian movement and so on. In this paper, we use the standard Wiener process and the Poisson process to simulate the fluctuation of the interest rate.

\section{The Anti-Inflation Life Insurance Actuarial Model}

\section{Symbol Description}

$\delta$ is the force of interest;

$i$ is the annual interest rate;

$(x)$ is the individual who is at the age of $x$;

$f_{T(x)}(t)$ is the probability density function of $T(x)$;

$f_{T(x y)}(t)$ is the probability density function of $T(x y)$;

$\mu_{x}$ is the ability of the death when an individual is at the age of $x$;

$T(x)$ is the future living time of the individual who is at the age of $x$;

${ }_{t} p_{x}$ is probability that an individual aged $x$ will live another $t$ years, then ${ }_{t} q_{x}=1-{ }_{t} p_{x}$; 
$T(x y)$ is the joint life of the couple, $(x)$ is the husband who is at the age of $x,(y)$ is the wife who is at the age of $y$.

\section{The Anti-Inflation Model}

The policy-holder is at the age of $x$, his future living time is T. Let the policy-holder buys $n$ years term life insurance, the holder pays the fee $m$ times per year for the same interval, the holder pays the equal fee at the beginning of each interval. The payment deadline is $n$ years, if the holder dies during the $n$ years, he stops paying. Let $C(t)$ be the payment function, the stochastic variable of the payment's present value is

$$
Z=\left\{\begin{array}{cc}
C(T) e^{-\delta(T)} & (0 \leq T \leq n) \\
0 & (T \geq n)
\end{array}\right.
$$

Consumer price index (CPI) is the macroeconomic indicator of the general household consumption of goods and services. In order to deal with inflation, insurance companies launch a variable life insurance; the insured amount will change with the time.

Table 1. The real purchasing power of two kind's life insurance fee

(Unit: Ten Thousand yuan)

\begin{tabular}{cccccccc}
\hline & 1980 & 1985 & 1990 & 1995 & 2000 & 2005 & 2010 \\
\hline$C_{1}(t)=1$ & 10.0 & 8.6 & 4.9 & 3.0 & 2.4 & 2.2 & 2.0 \\
$C_{2}(t)=e^{0.06 t}$ & 10.0 & 11.3 & 10.1 & 8.8 & 7.4 & 9.9 & 11.3 \\
The loss of $C_{1}(t)$ & 0 & 1.3 & 5.06 & 6.9 & 7.6 & 7.7 & 8 \\
The loss of $C_{2}(t)$ & 0 & 0 & 0 & 1.2 & 2.6 & 0.1 & 0 \\
\hline
\end{tabular}

In Tab.1, $C(t)=1$ is the equal insurance and $C(t)=e^{0.06 t}$ is the variable insurance. As can be seen from Tab.1, the longer the equal life insurance duration is, the more money the policy-holder loses. While the variable life insurance has a better ability to resist the risk, it can effectively resist the damage of inflation. From Tab.1, let $C(t)=e^{0.06 t}$ be the payment of variable insurance in this paper.

\section{The Force of Interest Accumulation Function}

In the paper, we use the Wiener process and Poisson process to simulate the fluctuation of the interest rate. Let the force of interest accumulation function be $\delta(t), \delta(t)$ is given by

$$
\delta(t)=\delta t+\alpha W(t)+\beta P(t) \quad(0 \leq t \leq \infty)
$$

where $W(t)$ follows standardized Wiener process, $P(t)$ follows Poisson process and the parameter is $\lambda, W(t)$ and $P(t)$ are mutual independent. $\delta, \alpha$ and $\beta$ are all real number, which are equal or greater than 0 .

\section{Lemmas}

Lemma 1. Assuming that $W(t)$ follows standardized Wiener process, $P(t)$ follows Poisson process and the parameter is $\lambda, W(t)$ and $P(t)$ are independent. $\delta, \alpha$ and $\beta$ are real number, which are equal or greater than 0 . If $\delta(t)=\delta t+\alpha W(t)+\beta P(t) \quad(0 \leq t \leq \infty)$, then 


$$
E\left(e^{b \delta(t)}\right)=\exp \left\{b \delta t+\frac{1}{2} \alpha^{2} b^{2} \sigma^{2}(t)+\lambda t\left(e^{b \beta}-1\right)\right\}=F(b, t)
$$

Lemma 2. Let $i$ and $j$ satisfy $0 \leq i<j$, then

$$
E(\exp \{b \delta(i)+b \delta(j)\})=F(b, j-i) \cdot F(2 b, i)
$$

\section{Installment Joint Life Insurance Actuarial Models with the Stochastic Interest Rate}

\section{Net Single Premium}

Let $\bar{A}_{x y: n \mid}^{1}$ be joint life insurance net single premium, $\bar{A}_{x y: n \mid}^{1}$ is given by

$$
\begin{aligned}
\bar{A}_{x y: n}^{1} & =E\left(Z_{t}\right)=E_{W} E_{P} E_{T}\left(C(t) e^{-\delta(t)}\right)=E_{\mathrm{W}} E_{P}\left(\int_{0}^{n} Z(t) f_{T}(x y)(t) d t\right) \\
& =E_{W} E_{P}\left(\int_{0}^{n} C(t) e^{-\delta(t)}{ }_{t} p_{x} \cdot t p_{y} \cdot\left(\mu_{x+t}+\mu_{y+t}\right) d t\right) \\
& =\int_{0}^{n} C(t) E\left(e^{-\delta(t)}\right){ }_{t} p_{x} \cdot{ }_{t} p_{y} \cdot\left(\mu_{x+t}+\mu_{y+t}\right) d t
\end{aligned}
$$

According to Lemma 1 and Lemma 2, we can get

$$
\bar{A}_{x y: \overline{n \mid}}^{1}=\int_{0}^{n} C(t) \exp \left\{-\delta t+\frac{1}{2} \alpha^{2} \sigma^{2}(t)+\lambda t\left(e^{-\beta}-1\right)\right\} \cdot{ }_{t} p_{x} \cdot{ }_{t} p_{y} \cdot\left(\mu_{x+t}+\mu_{y+t}\right) d t
$$

According to Formula (3), $\bar{A}_{x y: n \bar{n}}^{1}$ is expression as

$$
\bar{A}_{x y: \bar{n} \mid}^{1}=\int_{0}^{n} C(t) F(-1, t) \cdot{ }_{t} p_{x} \cdot{ }_{t} p_{y} \cdot\left(\mu_{x+t}+\mu_{y+t}\right) d t
$$

\section{Survivorship Annuity}

Annual Survivorship Annuity. $(x)$ and $(y)$ are in the state of joint life, they pay the fee at the beginning of the year, the amount is a unit of discrete joint life annuity. We mark the amount as \&y: $\bar{n}$ is given by

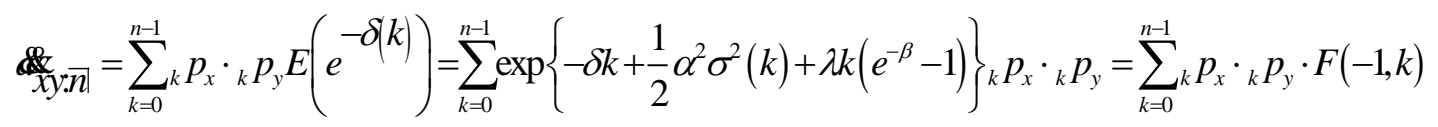

Monthly Survivorship Annuity. $(x)$ and $(y)$ are in the state of joint life, they pay the fee at the beginning of the month, the amount is a unit of discrete joint life annuity. We mark the amount as

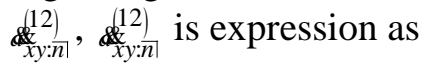

$$
\begin{aligned}
\frac{(12)}{x y: n \mid}= & \sum_{k=0}^{12 n-1} k / 12 p_{x}{ }_{k / 12} p_{y} E\left(e^{-\delta(k)}\right) \\
& =\frac{1}{12} \sum_{k=0}^{12 n-1} k / 12 p_{x}{ }_{k / 12} p_{y} \exp \left\{-\delta \frac{k}{12}+\frac{1}{2} \alpha^{2} \sigma^{2}\left(\frac{k}{12}\right)+\lambda \frac{k}{12}\left(e^{-\beta}-1\right)\right\}
\end{aligned}
$$




$$
=\frac{1}{12} \sum_{k=0}^{12 n-1} k / 12 p_{x} \cdot k / 12 p_{y} F\left(-1, \frac{k}{12}\right)
$$

\section{Net Level Premium}

Net Level Premium of Annual Payment of Life Insurance. $(x)$ and $(y)$ are in the state of joint life. Let $P\left(\bar{A}_{x y: \bar{n}}^{1}\right)$ be the annual net level premium, $P\left(\bar{A}_{x y: \bar{n}}\right)$ is given by

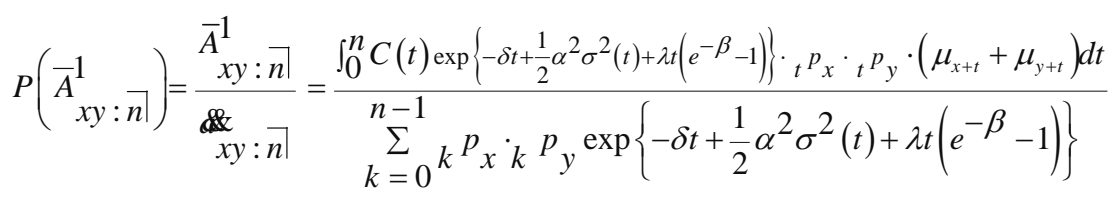

$$
\begin{aligned}
& =\frac{\int_{0}^{n} C(t) F(-1, t){ }_{t} p_{x} \cdot{ }_{t} p_{y} \cdot\left(\mu_{x+t}+\mu_{y+t}\right) d t}{\sum_{k=0}^{n-1}{ }_{k} p_{x} \cdot{ }_{k} p_{y} F(-1, k)}
\end{aligned}
$$

Net Level Premium of Monthly Payment of Life Insurance. $(x)$ and $(y)$ are in the state of joint life, let ${ }_{P}^{(12)}\left(\bar{A}_{x y: n)}^{1}\right)$ be the monthly net level premium, $P^{(12)}\left(\bar{A}_{x y: n}^{1}\right)$ is given by

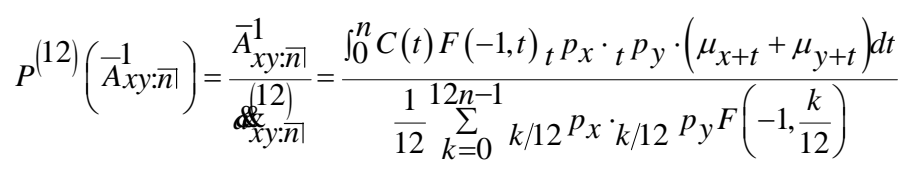

\section{Reserve of the Insurance Company}

Reserve of Annual Payment of Life Insurance. In the state of joint life, let ${ }_{c} L_{x y}$ be the future loss of insurance company at the time $c,{ }_{c} L_{x y}$ is given by

$$
{ }_{c} L_{x y}=C(c+J) e^{-\delta(J)}-P\left(\bar{A}_{x y: \bar{n} \mid}^{1}\right) \cdot{ }_{x y: J+1}
$$

where $J$ is the future living time of $(x y)$ at the time $c$.

Let ${ }_{c} V_{x y}$ be the reserve of the insurance company at the time $c$, we can get

$$
\begin{aligned}
& { }_{c} V_{x y}=E\left({ }_{c} L_{x y}\right) \\
& =\int_{0}^{n-c} C(c+t) E\left(e^{-\delta(c+t)}\right)_{t} P_{x+c} \cdot{ }_{t} P_{y+c} \cdot\left(\mu_{x+c+t}+\mu_{y+c+t}\right) d t-P\left(\bar{A}_{x y: n}^{1}\right) E\left(\sum_{k=0}^{n-c-1} I_{\{J \geq K\}} e^{-\delta(k)}\right) \\
& =\int_{0}^{n-c} C(t) F(-1, t)_{t} p_{x+c} \cdot{ }_{t} p_{y} \mu_{y+c} \cdot\left(\mu_{x+c+t}+\mu_{y+c+t}\right) d t \\
& -\frac{\int_{0}^{n} C(t) F(-1, t){ }_{t} p_{x} \cdot{ }_{t} p_{y} \mu_{y} \cdot\left(\mu_{x+t}+\mu_{y+t}\right) d t}{\sum_{k=0}^{n-1}{ }_{k} p_{x} \cdot{ }_{k} p_{y} F(-1, k)} \cdot \sum_{k=0}^{n-c-1}{ }_{t} p_{x+c} \cdot{ }_{t} p_{y+c} \cdot F(-1, k)
\end{aligned}
$$


Reserve of Monthly Payment of Life Insurance. In the state of joint life, let ${ }_{c}{ }^{L_{x y}}(12)$ be the future loss of insurance company at the time $\left.c,{ }_{c}{ }^{(12)}{ }_{x y}^{12}\right)$ is given by

$$
{ }_{c} L_{x y}^{(12)}=C(c+J) e^{-\delta(J)}-P^{(12)}\left(\bar{A}_{x y: n}^{1}\right) \cdot \frac{\left(\phi^{2}\right)}{x y: J+1}
$$

Let ${ }_{c} V_{x y}^{(12)}$ be the reserve of the insurance company at the time $c$, we can get

$$
\begin{aligned}
{ }_{c} V_{x y}^{(12)}= & \int_{0}^{n-c} C(c+t) F(-1, t)_{t} p_{x+c} \cdot{ }_{t} p_{y+c} \cdot\left(\mu_{x+c+t}+\mu_{y+c+t}\right) d t \\
& -\frac{\int_{0}^{n} C(t) F(-1, t){ }_{t} p_{x} \cdot{ }_{t} p_{y} \cdot\left(\mu_{x+t}+\mu_{y+t}\right) d t}{\sum_{k=0}^{12 n-1}{ }_{k / 12} p_{x} \cdot{ }_{k / 12} p_{y} F\left(-1, \frac{k}{12}\right)} \cdot \sum_{k=0}^{12(n-c)-1} k_{k / 12} p_{x+c} \cdot{ }_{k / 12} p_{y+c} \cdot F\left(-1, \frac{k}{12}\right)
\end{aligned}
$$

\section{Conclusions}

This paper studies the installment joint life insurance actuarial models with the stochastic interest rate. Firstly, according to the analysis of China's consumer price index data, the paper points out the impact of price increases to policy-holders, then put the consumer price index into the life insurance actuarial models and construct life insurance actuarial models. The model has the capacity of anti-inflationary. Secondly, the paper builds joint life insurance actuarial models. It discusses the annual and monthly payment with the stochastic interest rate. Thirdly, this paper present the model about the insurance company reserves. The model we proposed provides a method to determine the loss of life insurance company in future.

\section{Acknowledgement}

This research was financially supported by the Graduate Training Fund of Harbin Engineering University.

\section{References}

[1] Panjer H H, Bellhouse D R. Stochastic modeling of interest rate with applications to life contingencies [J]. Journal of Risk and Insurance, pp. 91-110, 1980.

[2] Beekman J A, Fuelling C P. Interest and mortality randomness in some annuities [J]. Insurance: Mathematics and Economics, 9(2), 185-196P, 1990.

[3] Qingrong Jiang. Whole Life Insurance with the Stochastic Interest Rate [J]. Journal of Hangzhou University, 24(2), pp.95-99, 1997.

[4] Wenjiong He, Qingrong Jiang. Increasing Life Insurance with the Stochastic Interest Rate [J]. Journal of Applied Mathematics, 13(2), pp.145-152, 1998.

[5] Jing Wei, Yongmao Wang. The Reserve of Continuous Increasing Life Insurance with the Stochastic Interest Rate [J]. Journal of Yanshan University, 30(2), pp.122-124, 2006. 